\section{Creating spaces of empathy
in the face of regimes of control \\ Creating spaces of empathy
in the face of regimes of control}

Global Studies of Childhood

2016, Vol. 6(1) II3-122

(C) The Author(s) 2016

Reprints and permissions: sagepub.co.uk/journalsPermissions.nav DOI: $10.1177 / 2043610615627928$ gsc.sagepub.com

@SAGE

\title{
Jenny Ritchie
}

Victoria University of Wellington, New Zealand

\begin{abstract}
This article focuses on the context of early childhood education in Aotearoa (New Zealand). It argues that greater consideration be given to the recognition of the ongoing intergenerational trauma resulting from histories of colonisation, particularly with regard to early childhood care and education pedagogies. It critiques the introduction of the US programme, the 'Incredible Years', since the behaviourist stance of its strategies lack empathy, and contradict the philosophy of the relationally based New Zealand early childhood curriculum, Te Whāriki.
\end{abstract}

\section{Keywords}

Aotearoa, early childhood education, empathy, Incredible Years, intergenerational trauma, New Zealand, Te Whāriki

\section{Introduction}

Aotearoa New Zealand has a history of colonisation which has resulted in both historical and ongoing trauma for the Indigenous peoples, the Māori (Pihama et al., 2014). Historical intergenerationally transmitted trauma includes dislocation from lands and resources, loss of language and tribal knowledges, and subjugation within the education and wider social systems. Many Māori children are also intergenerational victims of incarceration (Expert Avisory Group on Solutions to Child Poverty, 2012). Aotearoa New Zealand is also the home of many people from a range of Pacific Island backgrounds, and many of these islands are former colonies, with their own varied histories of sometimes multiple colonisations. Furthermore, changes to New Zealand immigration policies over the past two decades have generated a situation of cultural and linguistic superdiversity (Royal Society of New Zealand, 2013).

In 2003, the New Zealand Ministry of Education introduced a USA programme called 'The Incredible Years', a behaviour management training programme developed to teach strategies to parents and teachers of children 'with conduct problems' (Sturrock and Gray, 2013: 4). It is included within the 'Priority one' 'operating intention', of the Ministry's 2013-2018 'Statement of 
Intent', which is 'Improving education outcomes for Māori students, Pasifika students, students with special education needs and students from low socio-economic areas' (New Zealand Ministry of Education, 2013b: 18). The 'Incredible Years' is a behaviourist programme, based in 'social learning theory, particularly the coercion hypothesis of reinforcement developing and maintaining deviant behaviour and the notions of modelling and self-efficacy' (Sturrock and Gray, 2013: 10). It particularly targets Māori children and families, since 'Māori children have higher rates (15\% to 20\%) of conduct problems than non-Māori' (Sturrock and Gray, 2013: 5).

In this article, I problematise the introduction of this programme, in relation to its relevance to the Aotearoa (New Zealand) context, and in particular to Māori children and families. It will be argued that what has been chronically lacking throughout the colonisation process is empathy on the part of the Pākehā (European) colonisers towards Māori, and that this lack of empathy is an endemic component of the coloniser mind-set. Furthermore, the education system is perpetuating the ongoing trauma of historical colonisation, re-colonising Māori children and families, through imposing Western behaviourist programmes such as the 'Incredible Years' which focus on modifying children's conduct, rather than modelling sensitive, respectful, compassionate, empathic relationality.

\section{Erosion of empathy: Colonisation, trauma, empathy deficit and historical amnesia}

Empathy has been described as 'one of the most valuable resources in our world [italics in original]' since '[w]ithout empathy we risk the breakdown of relationships, we become capable of hurting others, and we can cause conflict. With empathy, we have a resource to resolve conflict, increase community cohesion and dissolve another person's pain' (Baron-Cohen, 2011: 130). Empathy and other aspects of emotional intelligence are significant components of infants', toddlers' and young children's brain and moral development and contribute to later academic achievement (Baron-Cohen, 2011; Grille, 2008; Qualter et al., 2012; Sims, 2009). 'Erosion of empathy is an important global issue related to the wellbeing of our communities, be they small (like families) or big (like nations)' (Baron-Cohen, 2011: 130).

It can be argued that, in relation to the historical ongoing traumatic impact on Māori of histories of colonisation, Pākehā, New Zealanders of European descent, appear to be largely bereft of empathy towards Māori, regarding this situation. 'Māori are grossly over-represented in New Zealand trauma profiles' (Pihama et al., 2014: 256). Due to a hegemonic historical amnesia perpetuated by the Pākehā majority (Giroux, 1983; Shadbolt, 1999), there is only limited awareness in the wider society of 'the history of colonization and the severity of the traumatic acts perpetrated against Māori' (Pihama et al., 2014: 257). The negative contemporary social statistics for Māori are thus not read by the general populace as an indictment of the impact of colonisation, but instead perpetuate the 'blame the victim' racist attribution of fault to the afflicted individuals. The multiple layering of this historical and contemporary trauma profile is not considered or reflected in contemporary education policy for Māori, which maintains a relentless yet largely ineffectual pressure to accelerate 'success for Māori' (Controller and Auditor-General, 2013; Goren, 2009; New Zealand Ministry of Education, 2013a: 5). Unchallenged, uncritiqued, embedded racism is the 'elephant in the room', conveniently ignored by the whitestream majority, leaving their privileged position as beneficiaries of Māori disenfranchisement intact (Came and da Silva, 2011).

In recent years, liberal paternalism towards Māori in government policy and practice has been replaced by the harsher face of neoliberalism. Two examples impacting within the early childhood care and education (ECCE) sector are the current National government's 'Better Public Services' target of $98 \%$ ECCE participation and the 'Incredible Years' behaviour management programme for 
the ECCE sector. In line with the 98\% participation target, those in receipt of government social welfare benefits, many of whom are Māori, are now faced with compulsory ECCE for their children:

It is now mandatory for beneficiaries to ensure that their 3-5 year-old children are enrolled in and regularly attend a licensed ECCE service or that they themselves participate in a MSD [Ministry of Social Development]-approved early parenting programme [such as Incredible Years Parent]. If they fail to ensure their child's attendance, benefits can be reduced by up to $50 \%$. This compulsory ECCE attendance is not required of any children other than those of beneficiaries, and is imposed in a context in which the quality and relevance of the provision accessible to these children may be questionable, and even be found wanting by Government agencies such as the ERO [Education Review Office]. (Ritchie et al., 2014: 12)

These policies ignore the emotional realities of families who are very likely to be already experiencing significant stress, further trampling their mana (pride, esteem, authority) and rangatiratanga (independence, self-determination).

\section{Pedagogies affirming of emotion}

Suppression, denial and distortion of emotion is a particular characteristic of whitestream societies with colonialist histories such as Aotearoa New Zealand, and of the United States, United Kingdom, Canada and Australia, where the Incredible Years programme has also been implemented (Came and da Silva, 2011; Matias and Zembylas, 2014). Through colonisation, dominant cultures hegemonically impose their regimes of truth, including 'emotional rules' onto others. 'Emotional rules reflect power relations and thus are techniques for the discipline of human differences in emotional expression and communication' (Zembylas, 2006: 254). According to Michalinos Zembylas (2006), modernist western culture has not placed a great deal of emphasis on understanding

the social, cultural, historical, and political context in which the meanings of emotions are developed, including such aspects as power relations, historical conditions or individuals' membership of social groups (e.g., teachers), the role of media and cyberspace and so on. (Zembylas, 2006: 256)

Postmodernist views of emotion, however, recognise emotional experiences as valuable sources of knowledge, values and ethics, and as a basis for political action (Zembylas, 2006). DeleuzeGuattarian perspectives provide insight into the seductive desiring forces of capitalism (Deleuze and Guattari, 2004a, 2004b), provoking great challenges to the bland acceptance of the sterile economic rationalism of neoliberalism. Both modernist behaviourism and neoliberalism enforce suppression of emotional life and conformity to a prescribed set of 'acceptable' emotions, such as 'positive attitudes' and the expectation that 'negative' emotions (i.e. powerful emotions such as anger) should be controlled, suppressed, and suffered in silence (Zembylas, 2006).

The history of early childhood care and education sector internationally and in Aotearoa, is interspersed with examples of pedagogues and pedagogies which demonstrate recognition of the emotional component of 'care'. This is interesting in that it has occurred within a wider western ideological context of liberal humanist individualism, and the pursuit of 'naked economic selfinterest' (Rifkin, 2009: 48), whereby the psychological gaze has been dominated by the theories of white males, either turned inward by the likes of Freud and Maslow, or aimed at maintaining control via the behaviourism of Watson and Skinner.

In the 20th century, New Zealand education services had benefited from the ideas of several noted progressive thinkers. In 1937, Dr Susan Isaacs (1885-1948), then Head of the Department of Child Development at the London University's Institute of Education, visited New Zealand to contribute to 
a national conference focussed on the ideas of the international progressive education movement, the New Education Fellowship. She emphasised children's needs for emotional support, to be provided via patient adults offering them security, affection and opportunities for expressive play. Sylvia Ashton-Warner (1908-1984), was an idiosyncratic new entrants' teacher in 'Native Schools' for Māori children during the period of the 1930s and 1940s, when such progressive ideas were being promoted. She saw her classroom as serving as 'a plank in a bridge from one culture to another' (Ashton-Warner, 1980: 31) to enable Māori children to experience a successful transition into schooling. She considered that 'This transition made by Maori children is often unsuccessful. At a tender age a wrench occurs from one culture to another, from which either manifestly or subconsciously, not all recover' (p. 31). She viewed children's emotional wellbeing as manifesting two kinds of expression, one creative and the other destructive. When children were provided with opportunities for creative release, their destructive outlet would atrophy. Ashton-Warner developed an 'organic key word' pedagogy for teaching literacy, allowing the young Māori children to choose their own word, with 'ghost', 'kiss', 'knife' and 'bomb' examples of these choices (Ashton-Warner, 1980).

The New Zealand, early childhood curriculum, Te Whāriki, He whāriki mātauranga mō ngā mokopuna o Aotearoa (New Zealand Ministry of Education, 1996), recognises the validity of the language, culture, beliefs and values of the Indigenous people, the Māori, as having equal status alongside Western educational perspectives and pedagogies. It takes a holistic view of children's growth and learning, recognising the multifaceted inter-relatedness of emotional, cognitive, cultural, spiritual and physical wellbeing. The document stresses the importance of emotional attachment and support for infants, toddlers and young children. It recognises that toddlers' feelings can be intense and unpredictable and stresses that young children's growing capacity for coping with uncertainty is best 'anchored by emotional support' (p. 25). The 'Mana Atua - Wellbeing' strand of the curriculum requires that early childhood care and education educators ensure that children's 'emotional well-being is nurtured' (p. 15). Children are to be supported in gaining 'an ability to identify their own emotional responses and those of others; confidence and ability to express emotional needs; [and should be able to] trust that their emotional needs will be responded to' (p. 50).

\section{'Incredible years' in Aotearoa}

The Incredible Years programmes, one for parents of young children and the other for teachers, were developed by Carolyn Webster-Stratton and others at the University of Washington, United States. They have been implemented widely within the United States, the United Kingdom, Canada, Ireland, Norway, Denmark, Sweden, Australia and New Zealand (Sturrock and Gray, 2013). The Incredible Years teacher programme involves '14-20 weekly two hour sessions for teachers to strengthen teacher classroom management strategies' for teachers of children aged 3-8 years (The Werry Centre for Child and Adolescent Mental Health, 2015). It focuses on 'strengthening teacher classroom management strategies, promoting children's pro-social behaviour and school readiness, and reducing classroom aggression and non co-operation' (Casey, 2014: 2). The Ministry of Education describes the programmes as 'manualised with a defined accreditation structure for Incredible Years facilitators' (Casey, 2014: 1). Facilitator training for both programmes is a threeday course (The Werry Centre for Child and Adolescent Mental Health, 2015).

While the developer of the programme acknowledges the complexities of cultural differences (Webster-Stratton, 2009), the possibilities for these to be authentically and responsively recognised are constrained within the western, behaviourist framing. The principles of the programme are illustrated in the diagram below (Figure 1).

A behaviourist regime of control is evident in the focuses of the four modules of the parenting programme which provides strategies of 'praise and incentives', 'rules', 'limit setting, and 


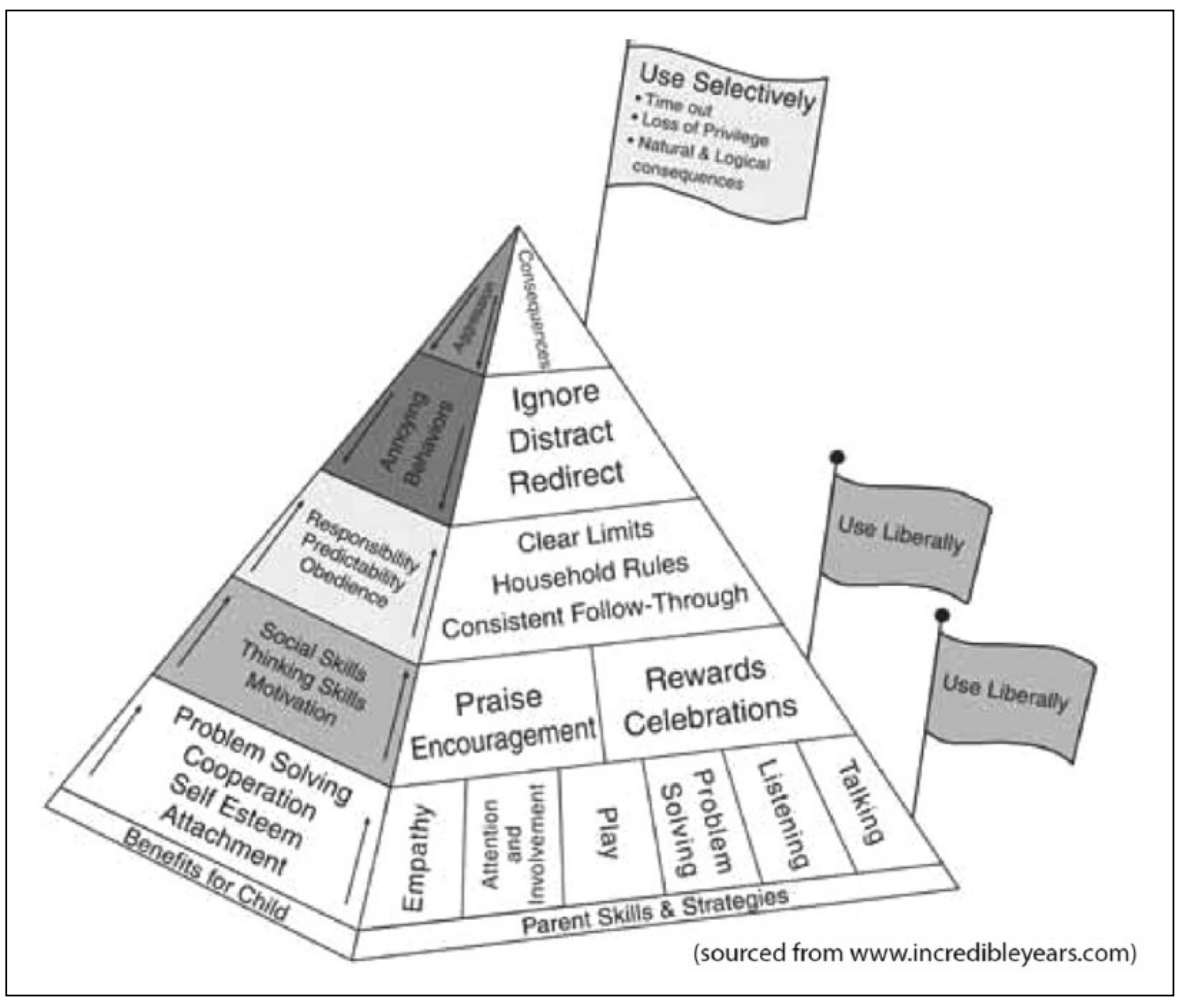

Figure I. Incredible Years Parenting programme pyramid. Source: Sturrock and Gray (2013: 10).

'positive discipline' in order to 'handle misbehaviour' and regulate the emotions of the children in their care (Dunn, 2012: 8). Interestingly, the programme also models the use of 'incentives' with the adult participants. This was appreciated by most but not all of the parents in a 2012 study of participants in the Central North Island Region:

There was always lots of prizes, chocolates and things. There was always a bowl of lollies and in the end it just kept on going around and around...but it was great, because I don't know, it just helped bring you closer together too cause it like, broke the ice, yeah. As I say food's always the way to getting people to talk eh. Put food there, they'll talk. (Māori completer)

It was good. It was like being a kid in a class room again but the treats were obtainable. (Non-Māori completer)

Oh yeah, the chocolate I went a bit hoha [annoyed] with the chocolates. Yeah well, it was like, oh, you know, you say something, la la la, and they go 'Oh good girl'. I was like oh I don't need this, gee you know, I'm not here for chocolates... like the teacher, you know, like the student thing going on. (Māori completer; as cited in Dunn, 2012: 19)

The numbers of Māori parents participating in the programme nationwide have been disproportionately high, that is, 35\%-38\% over the years 2010-2014 (Casey, 2014), while Māori make up approximately $16 \%$ of the general population. Yet, the completions for Māori have been lower than 
for non-Māori. For example, in 2012, in the Central North Island region, completion rates were 38/70 (54\%) Māori, and 82/115 (71\%) non-Māori (Dunn, 2012: 7). Reasons given by Māori parents who withdrew from the course included 'health issues, a new baby, sickness in the family', transport difficulties, or that the course was not suited to their particular child's age or disability factors (Dunn, 2012: 19). Some reported a cluster of such issues. Cultural dissonance was a further reason for withdrawal by Māori parents. Here is one participant's explanation:

It's more pakeha [European] than Mãori. ... Yes the programme. When I listened to the tutors, to me it doesn't fit right. To me it's like you don't know our kids. You know what I mean? Only the Māori people know their own children. (Māori withdrawer; Dunn, 2012: 20)

Māori participants who had withdrawn from the programme offered suggestions for improvement which included the provision of Māori facilitators, that the programme be based on local marae (Māori village meeting place), that the group of attendees comprise more Māori members, and that the course needed to better relate 'to a Māori approach and focus' (Dunn, 2012: 28). A further suggestion was that the vignettes utilised should be adapted to New Zealand situations.

A Ministry of Social Development's 2013 pilot study of the Incredible Years parent programme surveyed 166 parent and child participants (Sturrock and Gray, 2013). One third of the children and $23 \%$ of caregivers were Māori. Interestingly, $46 \%$ of the total parent participants self-reported highly for depression, $36 \%$ for stress and $13 \%$ for anxiety. While the parents of both Māori and non-Māori children reported sustained improvements in their children's behaviour, the effect sizes for Māori children were consistently smaller than those for non-Māori children, suggesting the IYP programme was less effective for Māori (Sturrock and Gray, 2013: 52). While most (92\%) of the Māori participants said they would recommend the course, only half $(53 \%)$ reported that they were 'using lessons learnt to improve their child's behaviour' (p. 71). The evaluation concludes that further work is required 'on maximising gains for Māori families, particularly in the maintenance of behaviour change' (p. 1). It also considers that the 'findings indicate the need for culturally responsive refinements to IYP programmes to ensure the maximum effectiveness for all parents and children and the maintenance of behaviour improvements' (p. 57).

A further, small-scale kaupapa Māori study involving four Māori mothers and four programme facilitators similarly concluded that 'work must be done to provide a more responsive, cohesive (and at times differentiated) and aligned approach to meet the needs of Māori families' (as cited in Sturrock and Gray, 2013: 59).

The New Zealand Ministry of Education is aware of these issues, and has embarked on providing 'cultural enhancements' to the Incredible Years programmes. The Ministry provided a written response to my question, 'Please outline the extent to which the programme has been modified to include Māori and Pacific Islands perspectives?':

Cultural enhancements are embedded into both Incredible Years programmes through a collaborative and parent and teacher-centred approach which seeks to value and respond to the heritage and tikanga [Mäori culture and values] of participants. (Casey, 2015: 2)

These 'cultural enhancements' are contracted externally. The Werry Centre of the University of Auckland has been contracted 'to provide workforce development and practice support to facilitators delivering the Incredible Years Parent programme' including an expectation to 'strengthen practice development so that the programme works for Māori and Pasifika' (Casey, 2014: 2). The Ministry also contracts iwi (tribal) organisations to deliver programmes to Māori. In addition: 
The Ministry is supporting an Incredible Years Teacher Cultural Enhancement Group which is focused on ensuring this programme works for Mãori. ... This group has also produced programme materials which is a further cultural enhancement. These resources are made available to all facilitators delivering the programme. (Casey, 2014: 2)

There are several interesting features that can be problematised drawing from the above admittedly fragmentary glimpse into the Incredible Years programmes' application in Aotearoa New Zealand. One is the globalising, genericising aspect of bringing this USA programme, with its historical antecedents in Western, individualistic behaviourism, and inherent assumptions of authoritarian power effects and suppression of emotion, into our specific context of the intergenerational trauma of colonisation. Another is the expectation that such a programme can be effectively modified by generating 'cultural enhancements' in order to become culturally relevant, and the extent to which these modifications might contribute to sustaining Māori ways of being, knowing, doing and relating which include upholding mana (pride, esteem, authority) and rangatiratanga (independence, self-determination).

\section{Discussion}

In this section I offer critiques from three different perspectives, of the use of programmes like Incredible Years in contexts such as Aotearoa New Zealand. The first critique is of behaviourism. The next discussion focus is of the appropriateness of using behaviourist methodology in a context of intergenerational trauma, with its concomitant suppression of emotion. Lastly, the issue of cultural relevance will be briefly canvassed.

\section{Behaviourism}

With the current era of hegemonic, globalised neoliberalism, holistic, humanistic modes of teaching and learning such as those espoused by Isaacs and Ashton-Warner are being pushed aside, being replaced by de-humanising technologies of governmentality such as military-styled charter schools (Goodman, 2013; Moir, 2014). We are seeing a dramatic shift to 'a technocratic, top-down micromanagement of education and, by implication, of children' (MacNaughton et al., 2007: 39). Children's 'achievement' of the standardised teaching content is harshly enforced, and in order to 'preserve the regulations ... rewards and sanctions are constantly administered' (Goodman, 2013: 91). The Incredible Years programme notes for participants include, for example, homework on effective limit setting that states 'PRAISE your child for complying with commands (or set up a reinforcement program for compliance)', and a model of 'Using Time Out for Compliance Training' (Webster-Stratton, 2015). These authoritarian, rigid models homogenise and objectify children, rather than recognising and responding to particularities of complex, hybrid, fluid subjectivities (Ladson-Billings, 2014). The veiled power dynamics of behaviourism contributes to sanitising and repressing the 'dynamic ecologies' (Tuck, 2010: 639) of the specific assemblages of children's and families' lives. There is no room here for acknowledgement of the multiplicities of children's emotions and desires. While desire can be spontaneous, rebellious, unpredictable and disruptive, behaviourism is not an epistemology that allows for the 'unanticipated, the uninvited, the uncharted, and unintended' (Tuck, 2010: 641). Neither facilitators nor teacher, parent or children's particular feelings and needs will necessarily be met, notwithstanding the promise of rewards of prizes, chocolates and lollies.

\section{Suppression of emotion in a context of intergenerational trauma}

Emotion is a central part of our human-ness, informing our sense of wellbeing, our meaning-making, and our ability to relate well with others. The Incredible Years programme offers behaviourist 
solutions to 'misbehaviours' that appear to be devoid of empathy for the contextual situation and emotions that may have contributed to the 'problem' behaviour: 'Reinforcements (praise, tangible rewards, play sessions); discipline (ignore, Time Out, etc.); and Techniques that help parents maintain self-control' (Webster-Stratton, 2015). It advises parents to ignore a child's tantrum, instructing 'No matter how long the storm lasts, don't give in or negotiate' (Webster-Stratton, 2015). Furthermore, love is to be offered as one of the rewards for compliance: 'Give your child attention and praise for positive behaviour; Redirect your child's negative behaviour' (Webster-Stratton, 2015). These methods are offering teachers, parents, and children emotional rules (Zembylas, 2006) that aim to ignore and suppress 'negative' emotions, denying the reality of pain, anger, sadness, grief, frustration, and the unmet needs that these represent. Trauma may manifest in serious expression such as psychosis when there have not been opportunities to name and express strong emotions and understand the meanings that are associated with the particular interpersonal, cultural and historic contexts (Charles and O'Loughlin, 2012). Considered in a context of intergenerational colonialist trauma, this enforcement of emotional de-sensitisation can only compound layers of sorrow and resentment on the part of Māori parents who attend such programmes, particularly when sessions are not facilitated by Māori group leaders.

\section{Cultural relevance}

The entrenched nature of the impacts of colonisation, which have generated ongoing cycles of poverty and marginalisation, require major social and educational policy changes in order to disrupt the hegemony of dichotomised power relations (Boston and Chapple, 2014; Dale et al., 2013; Ladson-Billings, 2014). While early childhood education is a fundamental and crucial site for establishing foundational learning dispositions, this process is unavoidably occurring within the constraints of the wider social, economic and political context, which reflect ongoing effects of colonialist oppression. Culturally decontextualized, regimented ('manualised') educational and parenting programmes, in replicating and enforcing dichotomised power relations and social strata and ignoring the histories that have created these inequities, are unlikely to have significant effects in disrupting cycles of poverty and disenfranchisement (Ladson-Billings, 2014).

Recognition by educational programmes of cultural/political histories of children, families and communities should be nuanced and specific to particular groups and places. In addition, responsiveness to the complex, hybrid, fluid identities produced by the multi-layered superdiversity of the New Zealand education context (Royal Society of New Zealand, 2013) requires deeply engaged, sensitive, and reflexive pedagogies implemented by well-qualified practitioners (Ladson-Billings, 2014).

\section{Concluding thoughts}

The specific historical, social, political, economic and cultural context(s) for education and parenting in Aotearoa New Zealand, have generated some unique 'flax-roots' responses to particular situations. While the imported British-based schooling system followed its regimented antecedent, the early childhood care and education sector was less constrained. Led by women who aimed to meet identified needs such as a lack of care and education, support for parents, or the urgency of language revitalisation, models such as the Free Kindergarten, Playcentre, and Kōhanga Reo movements arose and were sustained during the 20th century. These are now under threat as government policy has resituated the early childhood care and education sector as a private 'industry', albeit with heavy taxpayer funded subsidies for the burgeoning profit-making private providers. 'Success for Māori children' and other 'priority learners' (Ministry of Education, 2014), while a laudable aim, is unlikely to be achieved by adopting hierarchical, authoritarian, disempowering, normalising pedagogical modes that target the labelled group as being in deficit, while ignoring the wider 
histories, and concomitant trauma, as contributing factors. Michalinos Zembylas has called for reconceptualised 'landscapes of action' which will include 'the creation of new emotional rules that nurture and advance new pedagogies' (Zembylas, 2006: 268). These new 'emotional rules' could constitute a trauma-informed approach that reflects and models compassion, respect, engaged listening, and empathy. Privileging these dispositions would allow us to 'reformulate discourse and practice and contribute to locating strategies that potentially can move teachers and students away from being normalized', generating 'new ways of performative subjectivities' (Zembylas, 2006: 268). Drawing upon local Indigenous onto-epistemologies, rather than western behaviourism, can illuminate pathways for caring for ourselves, one another, our more-than-human co-habitors, and the planet Earth itself (Ritchie, 2013).

\section{Funding}

The author(s) received no financial support for the research, authorship and/or publication of this article.

\section{References}

Ashton-Warner S (1980) Teacher: The Testament of an Inspired Teacher. London: Virago.

Baron-Cohen S (2011) Zero Degrees of Empathy: A New Theory of Human Cruelty and Kindness. London: Penguin.

Boston J and Chapple S (2014) Child Poverty in New Zealand. Wellington, New Zealand: Bridget Williams Books.

Came HA and da Silva S (2011) Building political competencies for the transformation of racism in Aotearoa. Kōtuitui: New Zealand Journal of Social Sciences Online 6(1-2): 113-123.

Casey K (2014) Response to Author Enquiry re Incredible Years and Released Under the Official Information Act, November 5. Wellington: New Zealand Ministry of Education.

Charles M and O'Loughlin M (2012) The complex subject of psychosis. Psychoanalysis, Culture \& Society 17(4): 410-421.

Controller and Auditor-General (2013) Education for Māori: Implementing Ka Hikitia - Managing for Success. Wellington, New Zealand: Office of the Auditor-General. Available at: http://www.oag.govt. nz/2013/education-for-maori

Dale MC, O'Brien B and St John S (2013) Our Children, Our Choice: Priorities for Policy. Auckland, New Zealand: Child Poverty Action Group.

Deleuze G and Guattari F (2004a) Anti-Oedipus: Capitalism and Schizophrenia (trans. R Hurley, M Seem and HR Lane). London and New York: Continuum.

Deleuze G and Guattari F (2004b) A Thousand Plateaus: Capitalism and Schizophrenia (trans. B Massumi). London and New York: Continuum.

Dunn L (2012) Research report into Māori and non-Māori retention in Incredible Years Parent Programme, Central North Region. Wellington, New Zealand: New Zealand Ministry of Education, Special Education.

Expert Avisory Group on Solutions to Child Poverty (2012) EAG Working Paper No. 14: Reducing Child Poverty in Maori Whanau. Wellington: Office of the Children's Commissioner. Available at: http:// www.occ.org.nz/publications/expert-advisory-group/?category $=12$

Giroux H (1983) Theory and Resistance in Education: A Pedagogy for the Opposition. London: Heinemann Educational Books.

Goodman JF (2013) Charter management organizations and the regulated environment: Is it worth the price? Educational Researcher 42(2): 89-96.

Goren PD (2009) How Policy Travels: Making Sense of Ka Hikitia-Managing for Success: The Mãori Education Strategy 2008-2012. Wellington, New Zealand: Ian Axford (New Zealand) Fellowships in Public Policy.

Grille R (2008) Parenting for a Peaceful World (Revised ed.). Richmond: The Children's Project.

Ladson-Billings G (2014) Culturally relevant pedagogy 2.0: A.k.a. the Remix. Harvard Educational Review 84(1): 74-84.

MacNaughton G, Hughes P and Smith K (2007) Rethinking approaches to working with children who challenge: Action learning for emancipatory practice. International Journal of Early Childhood 39(1): 39-57. 
Matias CE and Zembylas M (2014) 'When saying you care is not really caring': Emotions of disgust, whiteness ideology, and teacher education. Critical Studies in Education 55(3): 319-337.

Ministry of Education (2014) Focus on Priority Learners. Wellington, New Zealand: Ministry of Education. Available at:http://www.minedu.govt.nz/theMinistry/EducationInitiatives/InvestingInEducationalSuccess/ Report/Part2/FoundationElements/Focus.aspx

Moir J (2014) Charter school defends drop in roll (Dominion Post). Available at: http://www.stuff.co.nz/ national/education/63695078/Charter-school-defends-drop-in-roll

New Zealand Ministry of Education (1996) Te Whāriki. He whāriki mātauranga mō ngā mokopuna o Aotearoa: Early childhood curriculum. Wellington, New Zealand: Learning Media. Available at: http:// www.educate.ece.govt.nz/ /media/Educate/Files/Reference\%20Downloads/whariki.pdf

New Zealand Ministry of Education (2013a) Ka hikitia. Accelerating Success. 2013-2017. The Mãori Education Strategy. Wellington, New Zealand: Ministry of Education. Available at: http://www.minedu. govt.nz/theMinistry/PolicyAndStrategy/KaHikitia.aspx

New Zealand Ministry of Education (2013b) Statement of Intent 2013-2017. Wellington, New Zealand: Ministry of Education. Available at: http://www.minedu.govt.nz/theMinistry/PublicationsAndResources/ StatementOfIntent/SOI2013.aspx

Pihama L, Reynolds P, Smith C, et al. (2014) Positioning historical trauma theory within Aotearoa New Zealand. AlterNative: An International Journal of Indigenous Peoples 10(3): 248-262.

Qualter P, Gardner KJ, Pope DJ, et al. (2012) Ability emotional intelligence, trait emotional intelligence, and academic success in British secondary schools: A 5 year longitudinal study. Learning and Individual Differences 22(1): 83-91.

Rifkin J (2009) The Empathic Civilization: The Race to Global Consciousness in a World in Crisis. New York: Penguin.

Ritchie J (2013) Indigenous onto-epistemologies and pedagogies of care and affect in Aotearoa. Global Studies of Childhood 3(4): 395-406.

Ritchie J, Harvey N, Kayes M, et al. (2014) Our Children, Our Choice: Priorities for Policy (Child Poverty Action Group Policy Paper Series. Part Two: Early Childhood Care \& Education (ECCE)). Auckland, New Zealand: Child Poverty Action Group. Available at: http://www.cpag.org.nz/resources-publications/our-children-our-choice-priorities-for-policy-7/

Royal Society of New Zealand (2013) Languages in Aotearoa New Zealand. Wellington, New Zealand: Royal Society of New Zealand. Available at: http://www.royalsociety.org.nz/expert-advice/informationpapers/yr2013/languages-in-aotearoa-new-zealand/

Shadbolt M (1999) From the Edge of the Sky: A Memoir. Auckland, New Zealand: David Ling Publishing.

Sims M (2009) Neurobiology and child development: Challenging current interpretation and policy implications. Australasian Journal of Early Childhood 34(1): 36-42.

Sturrock F and Gray D (2013) The Incredible Years Pilot Study Evaluation Report. Wellington, New Zealand: Ministry of Social Development.

The Werry Centre for Child and Adolescent Mental Health (2015) Research, Teaching and Workforce Development. Auckland, New Zealand: The Werry Centre for Child and Adolescent Mental Health, University of Auckland. Available at: http://www.werrycentre.org.nz/

Tuck E (2010) Breaking up with Deleuze: Desire and valuing the irreconcilable. International Journal of Qualitative Studies in Education 23(5): 635-650.

Webster-Stratton C (2009) Affirming diversity: Multi-cultural collaboration to deliver the Incredible Years parent programs. International Journal of Child Health and Human Development 2(1): 17-32.

Webster-Stratton C (2015) The Incredible Years Curriculum. Seattle, WA: Incredible Years. Available at: http://incredibleyears.com/programs/

Zembylas M (2006) Challenges and possibilities in a postmodern culture of emotions in education. Interchange 37(3): 251-275.

\section{Author biography}

Jenny Ritchie lectures at Victoria University of Wellington, New Zealand. Her teaching, research, and writing has focused on supporting early childhood educators and teacher educators to enhance their praxis in terms of cultural, environmental and social justice issues. 